Check for updates

Cite this: RSC Adv., 2018, 8, 39897

\title{
Efficient production of sugar-derived aldonic acids by Pseudomonas fragi TCCC11892 $\uparrow$
}

\begin{abstract}
Shuhong Mao, (D) a Yanna Liu, ${ }^{\mathrm{b}}$ Yali Hou, ${ }^{\mathrm{a}}$ Xiaoyu Ma, ${ }^{\mathrm{c}}$ Juanjuan Yang, ${ }^{\mathrm{c}}$ Haichao Han, ${ }^{\mathrm{b}}$ Jianlin Wu, ${ }^{\mathrm{b}}$ Longgang $\mathrm{Jia}^{\mathrm{a}}{ }^{\mathrm{b}}$ Huimin Qin (D)*ac and Fuping Lu (D) *ab

Aldonic acids are receiving increased interest due to their applications in nanotechnology, food, pharmaceutical and chemical industries. Microbes with aldose-oxidizing activity, rather than purified enzymes, are used for commercial production with limited success. Thus it is still very important to develop new processes using strains with more efficient and novel biocatalytic activities for the production of adonic acids. In the present study, Pseudomonas fragi TCCC11892 was found to be an efficient producer of aldonic acids, with the production of galactonic and L-rhamnonic acid by $P$. fragi reported for the first time. The semi-continuous production of maltobionic acid and lactobionic acid was developed for $P$. fragi TCCC11892, achieving a yield of over $90 \mathrm{~g} \mathrm{~L}^{-1}$ for the first 7 cycles. The excellent performance of $P$. fragi in the production of lactobionic acid $\left(119 \mathrm{~g} \mathrm{~L}^{-1}\right)$ was also observed when using waste cheese whey as an inexpensive fermentation medium. Scaling up of the above process for production of aldonic acids with P. fragi TCCC11892 cells should facilitate their commercial applications.
\end{abstract}

Received 11th September 2018 Accepted 18th November 2018

DOI: 10.1039/c8ra07556e

rsc.li/rsc-advances a workable approach to overcome the drawbacks associated with chemical or enzymatic oxidation. ${ }^{7-9}$

Aldonic acids could be produced from microorganisms with aldose-oxidizing activity found in many archaea and bacteria and some eukaryotes. ${ }^{\mathbf{1 , 2 , 1 0}}$ Recently, P. taetrolens has gained much attention as an efficient microbial platform for the production of lactobionic acid., ${ }^{\mathbf{4 , 8 , 1 1}}$ Various methodologies for optimizing bio-processing conditions have been designed to improve lactobionic acid yields. For example, Alonso et al. demonstrated the feasibility of using a novel flow cytometry approach for optimizing lactobionic acid production based on the physiological status of $P$. taetrolens cells. ${ }^{12}$ In addition, the $\mathrm{pH}$-control mode, seed culture as well as supply of oxygen have also been shown to be important parameters for optimizing the bio-production of lactobionic acid. ${ }^{11}$ However, more efficient processes for commercial bio-production of lactobionic acid on industrial scale still need to be explored.

Compared with lactobionic acid, bio-production of maltobionic acid has not been studied extensively. ${ }^{5}$ Maltobionic acid derived from maltose (8.9\% maltose) incubated with Pseudomonas graveolens for 50 hours was documented. ${ }^{13}$ In addition, cellobionic and L-rhamnonic acids are also considered to have great potential as replacements for certain petrochemicals in the future. ${ }^{\mathbf{1 1 4 , 1 5}}$ In fact, the introduction of these aldonic acids into commerce is still limited due to the low efficiency of currently reported biocatalysts. ${ }^{16}$ Therefore, further screening and exploration of strains with novel biocatalytic activities plays an important role in the development of new processes for aldonic acid production that are both sustainable and efficient.
${ }^{a}$ Key Laboratory of Industrial Fermentation Microbiology, Ministry of Education, Tianjin University of Science \& Technology, Industrial Microbiology Laboratory, College of Biotechnology, Tianjin Economic and Technological Development Zone, No. 29, 13 Main Street, Tianjin 300457, China. E-mail: huiminqin@tust.edu.cn; lfp@tust.edu.cn; Fax: +86-22-60602298; Tel: +86-22-60601958

${ }^{b}$ State Key Laboratory of Food Nutrition and Safety, Tianjin University of Science \& Technology, Tianjin 300457, China

'Tianjin Key Laboratory of Industrial Microbiology, College of Biotechnology, Tianjin University of Science \& Technology, Tianjin 300457, China

$\dagger$ Electronic supplementary information (ESI) available. See DOI: 10.1039/c8ra07556e 
In this study, four Pseudomonas strains were investigated regarding their ability to produce aldonic acids. A process for semi-continuous production of lactobionic acid and maltobionic acid was developed. The efficient production of lactobionic acid was demonstrated using the industrial wasteproduct whey as the fermentation medium.

\section{Results and discussion}

\section{$P$. fragi is the most versatile sugar oxidizer among the tested Pseudomonas spp.}

Some aerobic bacteria, especially members of the genus Pseudomonas, can oxidize a wide range of aldose sugars into their corresponding aldonic acids by their dehydrogenase systems. ${ }^{1}$ $P$. taetrolens has recently been shown to be an efficient microbial platform for lactobionic acid production. ${ }^{8,9}$ In this study, four Pseudomonas bacteria strains were found to have the ability to produce adonic acids (ESI Fig. S1-S19†). As shown in Table 1, Pseudomonas ficuserectae TCCC11959 transformed maltose into maltobionic acid, and Pseudomonas beteli TCCC11961 produced maltobionic acid and lactobionic acid, respectively; and a wide range of aldose sugars were oxidized into their corresponding aldonic acids by cells of $P$. fragi TCCC11892.

Fig. 1 showed the optimal conditions for P. fragi cells catalyzed aldonic acid production using various aldoses, including $37{ }^{\circ} \mathrm{C}$, shaking speed of $200 \mathrm{rpm}$ and a cell concentration of 3 $\mathrm{g}_{\mathrm{DW}} \mathrm{L}^{-1}$, and in which the production efficiency was: maltobionic $>$ lactobionic $>$ galactonic $>$ cellobionic and L-rhamnonic acid.

It is noteworthy that we found for the first time that $P$. fragi was capable of producing L-rhamnonic acid from L-rhamnose, a deoxy sugar found widely in bacteria and some plants. ${ }^{17}$ Although high levels of L-rhamnonic acid production were reported for Candida polymorpha and Pichia robertsii using Lrhamnose as the substrate, the other main metabolic product of 1,2-propanediol was also observed at the same time, resulting in the difficulty in L-rhamnonic acid downstream processing. ${ }^{18}$

The fermentation product of cellobionic acid by $P$. fragi so far has not been reported. ${ }^{15}$ Cellobionic acid is an important intermediate during the degradation of cellulosic biomass by several lignocellulolytic fungi and bacteria. ${ }^{19}$ Its production

Table 1 Bioconversion of the indicated aldoses by Pseudomonas ficuserectae TCCC11959, Pseudomonas beteli TCCC11961, Pseudomonas agarici TCCC11962 and Pseudomonas fragi TCCC11892

\begin{tabular}{lllll}
\hline & TCCC11892 & TCCC11959 & TCCC11961 & TCCC11962 \\
\hline Glucose & - & - & - & - \\
Maltose & + & + & + & - \\
Lactose & + & - & + & - \\
Glucose & - & - & - & - \\
Galactose & + & - & - & - \\
Cellobiose & + & - & - & - \\
L-Rhamnose & + & - & - & - \\
Trehalose & - & - & - & - \\
Arabinose & + & - & - & - \\
Mannose & - & - & - & -
\end{tabular}

(a)

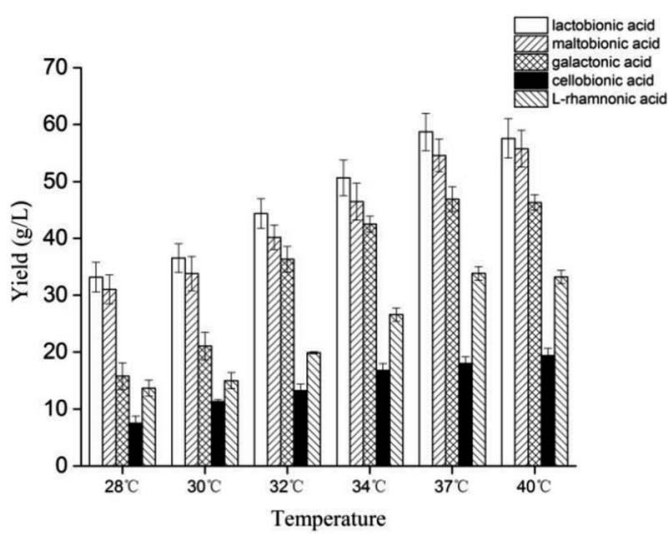

(b)

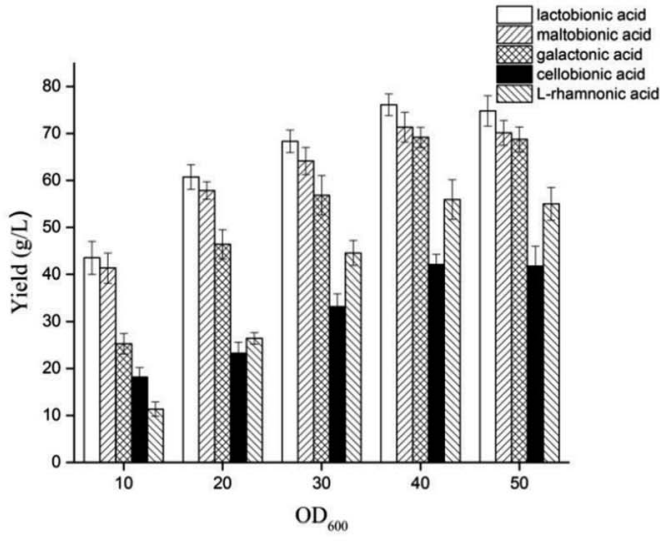

(c)

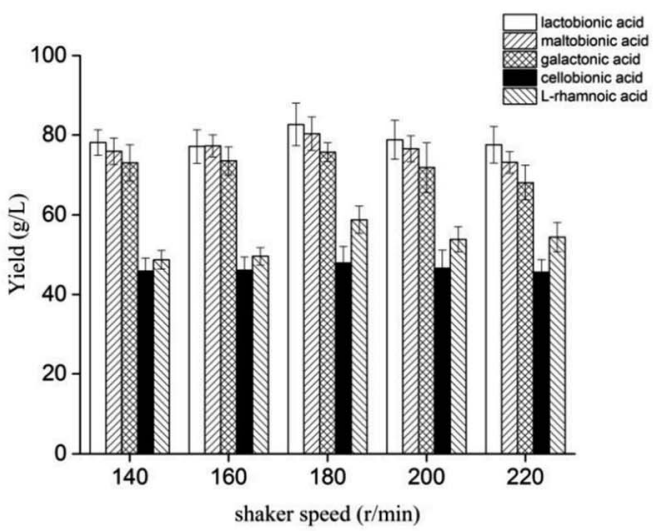

Fig. 1 The effects of temperature (a), cell concentration (b) and shaker speed (c) on the yield of aldonic acids from aldoses.

from cellobiose has been achieved using cellobiose dehydrogenase $(\mathrm{CDH})$ as well as the combined action of polysaccharide monooxygenase and cellobiohydrolase. ${ }^{20}$ Furthermore, cello- $^{-}$ bionic acid was identified in the culture supernatants of $F$. succinogenes S8. ${ }^{21}$ The reported most efficient producer of cellobionic acid, Gluconobacter frateurii NBRC3285, produced cellobionic acid with a yield of only about $3 \mathrm{mM}$ with the addition of $27.8 \mathrm{mM}$ cellobiose to the culture medium. ${ }^{\mathbf{1 0}}$ Herein, apparent improvement of the cellobionic acid production efficiency $\left(50 \mathrm{mg} \mathrm{L}^{-1}\right.$ ) was achieved using $P$. frag with addition of $1 \mathrm{~g} \mathrm{~L}^{-1}$ cellobiose in the culture. Further upgrade of the above 
process should have industrial applications for cellobionic acid production which can be used as a substrate to produce other valuable biochemicals. ${ }^{15}$

\section{Semi-continuous production of lactobionic acid and maltobionic acid using $P$. fragi TCCC11892}

The semi-continuous production of lactobionic acid using $P$. fragi TCCC11892 was carried out over ten cycles under the same reaction conditions. Fig. 2 indicated that the yield in the first 7 cycles remained over $91.7 \mathrm{~g} \mathrm{~L}^{-1}$ for lactobionic acid, while the yield in the last 3 cycles gradually decreased. The semicontinuous fermentation with cell recycle offers several advantages over batch fermentation when applied to the later generation lactobionic acid production, and the volumetric productivity was $3.8 \mathrm{~g} \mathrm{~L}^{-1} \mathrm{~h}^{-1}$ and the process reduced to $24 \mathrm{~h}$.

Maltobionic acid is currently mainly obtained from the chemical or enzymatic oxidation of maltose. Stodola and Lockwood first reported the aldonic acid production from maltose and lactose by Pseudomonas graveolens. ${ }^{13}$ On the other hand; the biochemical production of maltobionic acid using whole cell biocatalysts has not been reported in the literature. In this study, the yield of maltobionic acid is $94.7 \mathrm{~g} \mathrm{~L}^{-1}$, and this
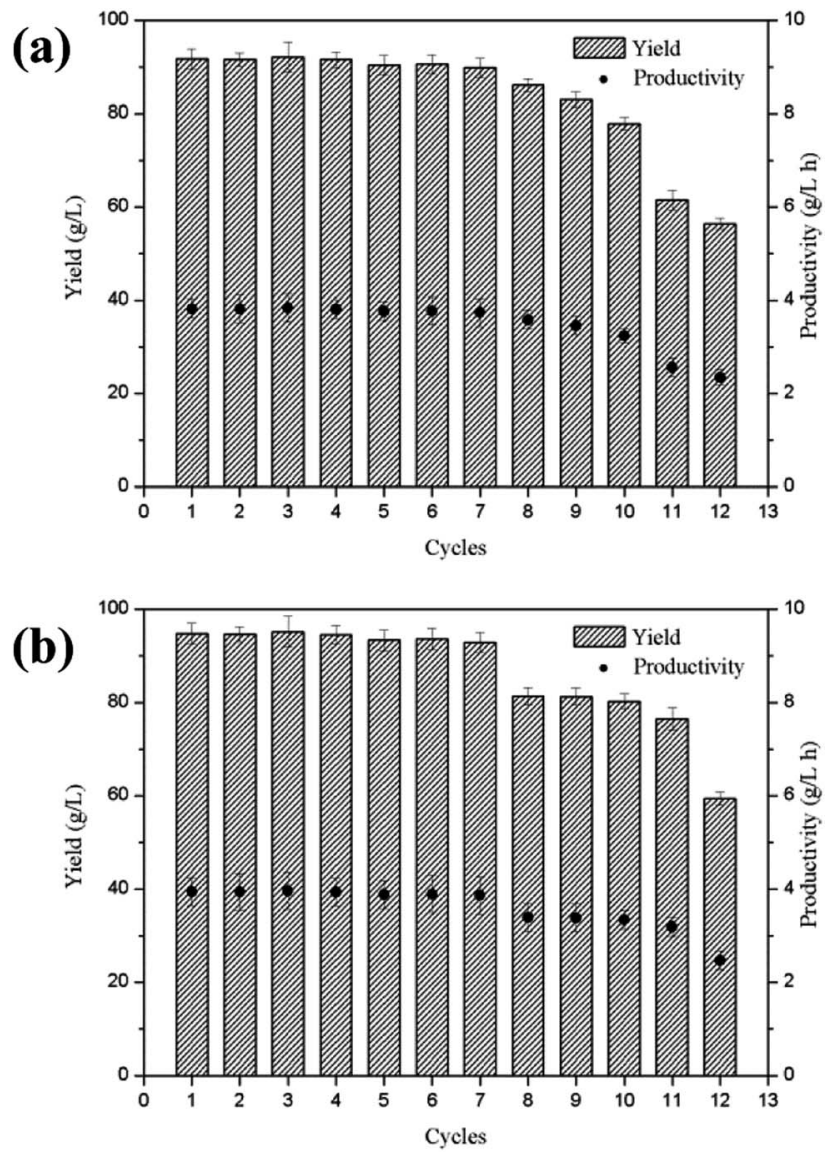

Fig. 2 Semi-continuous production of lactobionic acid (a) and maltobionic acid (b) using $P$. fragi in a $2 \mathrm{~L}$ bioreactor at $37^{\circ} \mathrm{C}, 180 \mathrm{rpm}$ and $\mathrm{pH} 6.5$. bio-process developed for maltobionic acid will be helpful for their potential applications in the marketplace.

\section{Highly efficient production of lactobionic acid using cheese whey}

Industrial waste whey from cheese production was used to produce lactobionic acid through a biotechnological process carried out by $P$. fragi. The results showed that lactobionic acid could be produced efficiently when $20 \%$ whey was used as the fermentation medium (Fig. 3). On the basis of shake-flask experiments, the lactobionic acid production was scaled up to a $2 \mathrm{~L}$ fermentor, and the effect of the dissolved oxygen concentration on the product yield was also investigated. The cell concentration reached as high as $1.6 \mathrm{~g}_{\mathrm{DW}} \mathrm{L}^{-1}$, and the lactobionic acid titer of $119 \mathrm{~g} \mathrm{~L}^{-1}$ was obtained after $36 \mathrm{~h}$ fermentation when the dissolved oxygen concentration was $40 \%$. Compared with previous studies, the specific lactobionic acid productivity was clearly improved by the strain investigated in this study, with about a 1.6-fold increase $\left(3.3 \mathrm{~g} \mathrm{~L}^{-1} \mathrm{~h}^{-1}\right.$ versus $\left.2.1 \mathrm{~g} \mathrm{~L}^{-1} \mathrm{~h}^{-1}\right) .^{11}$
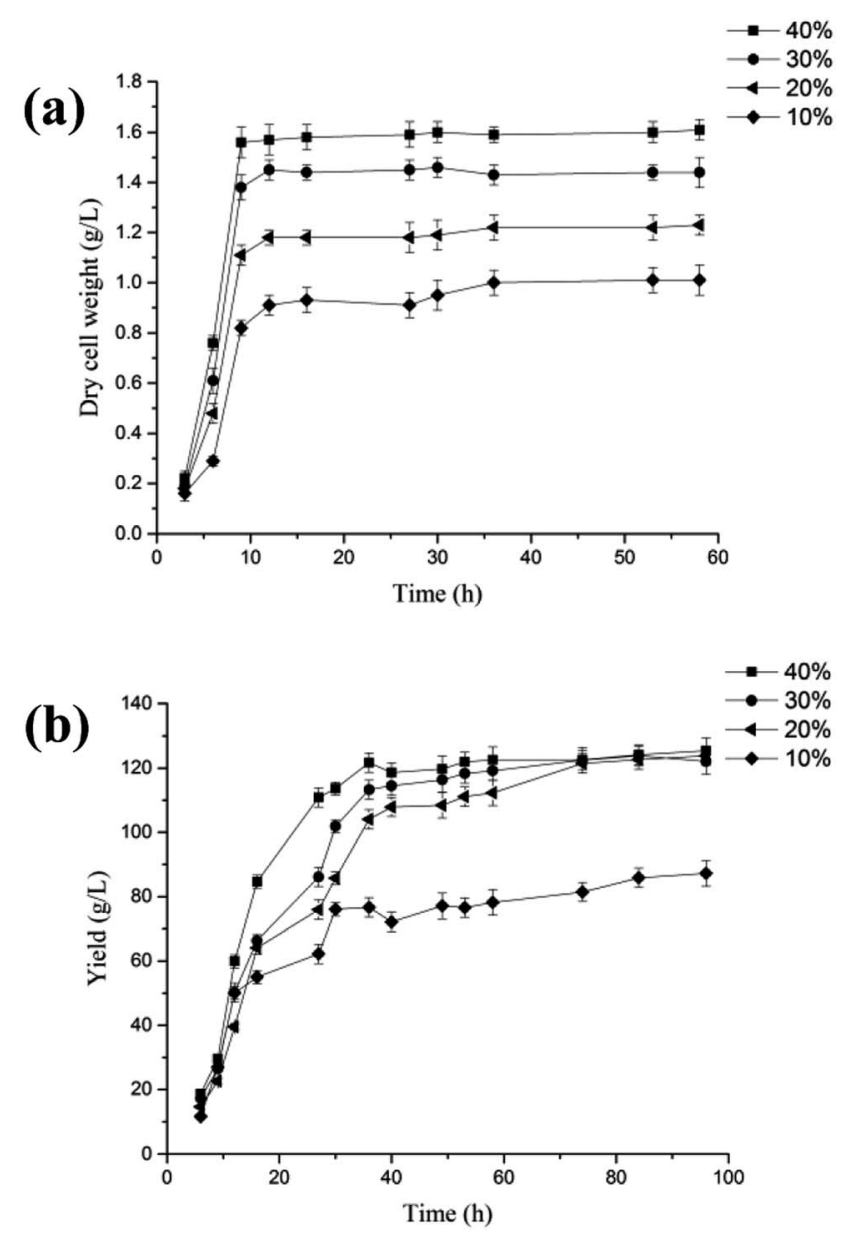

Fig. 3 Effect of the dissolved oxygen concentration on the cell concentration (a) and yield of lactobionic acid (b) using $20 \%$ dried powdered whey from cheese production in a $2 \mathrm{~L}$ bioreactor at $37^{\circ} \mathrm{C}$ and $\mathrm{pH} 6.5$. 
The promising commercial applications of lactobionic acid have prompted the development of a number of novel processes for its efficient biotechnological production., ${ }^{4,11,22}$ The present study thus demonstrates the feasibility of using $P$. fragi to achieve high-level bio-production of lactobionic acids from whey, providing an biocatalyst with the potential for more efficient industrial production of lactobionic acid.

\section{Experimental}

\section{Chemicals}

Galactose ( $\geq 98 \%)$, L-rhamnose monohydrate $(\geq 98 \%)$, maltose monohydrate $(\geq 98 \%)$, lactose monohydrate $(\geq 98 \%)$, and cellobiose $(\geq 90 \%)$ were purchased from Sangon Biotech Co. with and the standard product of $\mathrm{L}$-rhamnonic acid $(\geq 90 \%)$ and lactobionic acid $(\geq 97 \%)$ were purchased from Sigma-Aldrich Co.

\section{Screening of aldonic acid-producing strains}

Pseudomonas ficuserectae TCCC11959, Pseudomonas beteli TCCC11961, Pseudomonas agarici TCCC11692 and Pseudomonas fragi TCCC11892 were cultivated in YPD medium (without agar) for $10 \mathrm{~h}$ at $28{ }^{\circ} \mathrm{C}$ and $220 \mathrm{rpm}$. The cells were harvested and resuspended in physiological saline with the final cell concentration of $3 \mathrm{~g}_{\mathrm{DW}} \mathrm{L}^{-1}$. Then the biotransformation of solutions comprising $10 \%(\mathrm{w} / \mathrm{w})$ galactose, L-rhamnose, maltose, lactose, and cellobiose, separately, was carried out using resting cells individually. $\mathrm{Ca}_{2} \mathrm{CO}_{3}(1 \mathrm{~g} / 30 \mathrm{~mL})$ was used to adjust the acidity of the medium. The concentrations of the substrate and product were determined by HPLC.

\section{Separation and identification of aldonic acids}

After biotransformation, the fermentation medium was centrifugated at $4500 \mathrm{~g}$ for about $10 \mathrm{~min}$, and the supernatant was evaporated at $80{ }^{\circ} \mathrm{C}$. The resulting concentrated solution was precipitated with an equal volume of $95 \%$ ethanol, and the precipitate was filtered and dried at $60{ }^{\circ} \mathrm{C}$ for about $24 \mathrm{~h}$, after which the crude product was washed twice with ethanol and then filtered and dried. The final product was dissolved in $\mathrm{D}_{2} \mathrm{O}$ (99.9\%; Sigma, USA) and analyzed by ${ }^{1} \mathrm{H}$ NMR and ${ }^{13} \mathrm{C}$ NMR on an AV III $400 \mathrm{MHz}$ instrument (Bruker). Each product obtained from the biotransformation was also determined by means of ESI-mass spectroscopic analysis.

\section{Galactonic acid}

A molecular ion at $m / z=195.08$ (calc. $[\mathrm{M}-\mathrm{H}]^{+}$195.08) was found in the ESI-MS spectrum of the presumed galactonic acid sample, which was larger by 16 than that of galactose (180.16) (Fig. S1 $\dagger$ ), indicate oxidation. The structure of galactonic acid was confirmed by comparing its ${ }^{1} \mathrm{H}$ and ${ }^{13} \mathrm{C}$ NMR spectral data with reported values (Fig. S2 and $\mathrm{S} 3 \dagger)^{7}$

\section{L-Rhamnonic acid}

The product obtained from the biotransformation of L-rhamnose was determined by means of ${ }^{1} \mathrm{H}$ NMR and ${ }^{13} \mathrm{C}$ NMR analysis and it was identified as L-rhamnonic acid by comparing it with the spectral data of the commercially available L-rhamnonic acid reference standard (Fig. S4-S7†). This result was further corroborated by ESI-mass spectroscopic analysis (ESI: calc. $[\mathrm{M}-\mathrm{H}]^{+}$179.13, found 179.13; Fig. S8 $\dagger$ ), which displayed a molecular mass larger by 16 than that of L-rhamnose, perfectly fit the calculated molecular weight of rhamnonic acid.

\section{Maltobionic acid}

The ESI-MS spectrum of the presumed maltobionic acid analyte displayed a molecular ion at $m / z=357.25$ (calc. $[\mathrm{M}+\mathrm{H}]^{+}$ 357.25 ), which was larger by 16 than that of maltose (Fig. S9†). This suggested the oxidation of maltose (342.3). Both ${ }^{1} \mathrm{H}$ and ${ }^{13} \mathrm{C}$ data of the product of maltobionic acid (Fig. S10 and $\mathrm{S} 11 \dagger$ ) were in agreement with those published in the literature. ${ }^{7,23}$

\section{Lactobionic acid}

ESI-MS analysis indicated that the product obtained from the oxidation of lactose was larger by 16 than lactose (Fig. S12; $\dagger$ $357.22 v s$. 342.3) suggesting the insertion of one atom of oxygen into lactose. This product was further identified as lactobionic acid based on the ${ }^{1} \mathrm{H}$ NMR and ${ }^{13} \mathrm{C}$ NMR analysis, which showed the same spectra as the commercially available lactobionic acid reference standard (Fig. S13-S16†).

\section{Cellobionic acid}

In the case of the presumed cellobionic acid product, the molecular ion peak at $357.16\left(\left[\mathrm{M}^{+}\right]\right)$observed in the MS spectra was larger by 16 than that of the substrate, and this again suggested the oxidation of cellobiose (342.3; Fig. S17†). The ${ }^{1} \mathrm{H}$ NMR spectrum of cellobionic acid is shown in Fig. S18. $\uparrow$ The $\mathrm{H}$ signal from the terminal carbon present in the substrate disappeared in the product, confirming the oxidation of the substrate. Additionally, as can be seen from the ${ }^{13} \mathrm{C}$ NMR of the cellobionic acid product (Fig. S19†), an obvious downfield shift of the terminal carbon signal at $178 \mathrm{ppm}$ was observed, while the signal of the corresponding carbon disappeared at the same time, which suggests the introduction of a carboxylic acid group at the terminal carbon.

\section{Semi-continuous production of lactobionic and maltobionic acid using $P$. fragi}

Semi-continuous production of lactobionic acid and maltobionic acid using $P$. fragi was carried out with $10 \%$ lactose (or maltose) in the $2 \mathrm{~L}$ bioreactor equipped with a microfiltration membrane for cell recycling. In the first cycle, the cells were recycled back into the fermentation by microfiltration membrane unit after $24 \mathrm{~h}$ bioconversion, and the product stream was obtained at the same time. Then $10 \%$ lactose or maltose solutions was pumped to the bioreactor for the next batch of bioconversion, and the product obtained from each batch was analyzed by HPLC. 
Bio-production of lactobionic acid by $P$. fragi using cheese whey in a $2 \mathrm{~L}$ bioreactor

Batch cultivation was conducted in a $2 \mathrm{~L}$ bioreactor (INFORS HT Multifors Bench-Top Bioreactors, USA) with a working volume of $1 \mathrm{~L}$ at $37^{\circ} \mathrm{C}$, pH 6.5 and an agitation rate of $350 \mathrm{rpm}$. A $10 \%$ inoculation volume of the seed culture was transferred into medium containing whey from cheese production. In the beginning of the cultivation, the dissolved oxygen was left uncontrolled, and it decreased quickly due to rapid cell growth. Subsequently, the bio-production of lactobionic acid was carried out at different dissolved oxygen concentrations, from $10 \%$ to $40 \%$.

\section{Analytical methods}

HPLC analysis of the transformation products was performed at $25{ }^{\circ} \mathrm{C}$ on an SP 8800 liquid chromatography system (1260 Infinity LC, Agilent, USA) equipped with a refractive index detector (All Tech ELSD 2000 ES, Evans). The column (Prevail Carbohydrate ES $4.6 \times 50 \mathrm{~mm} 5 \mu$, Grace) was eluted with $60: 40$ $(\mathrm{v} / \mathrm{v})$ acetonitrile: $\mathrm{H}_{2} \mathrm{O}$ containing $0.1 \%$ of phosphoric acid at a flow rate of $1 \mathrm{~mL} \mathrm{~min}^{-1}$. HPLC of all the transformation products such as L-rhamnonic acid, maltobionic acid and lactobionic acid was shown in Fig. S20-S22. $\dagger$

\section{Conclusion}

In conclusion, the $P$. fragi strain investigated in this study can be applied for the efficient production of many valuable aldonic acids, including cellobionic acid, galactonic and L-rhamnonic which were unknown for this species. A high lactobionic acid titer of $119 \mathrm{~g} \mathrm{~L}^{-1}$ was obtained using waste whey from cheese production as an inexpensive substrate. Furthermore, the efficient semi-continuous process for the production of maltobionic acid and lactobionic acids developed in this study will accelerate its potential applications in the marketplace.

\section{Conflicts of interest}

There are no conflicts to declare.

\section{Acknowledgements}

This work was financially supported by grants from the Natural Science Foundation of China (No. 21878233), the Tianjin Natural Science Fund (17JCYBJC23700) and Tianjin Support Plan Program of Science and Technology (16YFZCSY01040).

\section{References}

1 T. Mehtio, M. Toivari, M. G. Wiebe, A. Harlin, M. Penttila and A. Koivula, Crit. Rev. Biotechnol., 2016, 36, 904-916.

2 K. Arya and D. T. Masram, Mini-Rev. Org. Chem., 2016, 13, 198-205.

3 L. F. Gutiérrez, S. Hamoudi and K. Belkacemi, Int. Dairy J., 2012, 26, 103-111.

4 S. Alonso, M. Rendueles and M. Diaz, Bioresour. Technol., 2013, 134, 134-142.

5 K. Fukami, K. Kawai, S. Takeuchi, Y. Harada and Y. Hagura, Food Biophys., 2016, 11, 410-416.

6 B. A. Green, R. J. Yu and E. J. Van Scott, Clin. Dermatol., 2009, 27, 495-501.

7 F. Pezzotti and M. Therisod, Carbohydr. Res., 2006, 341, 2290-2292.

8 S. Alonso, M. Rendueles and M. Diaz, Bioresour. Technol., 2011, 102, 9730-9736.

9 S. Alonso, M. Rendueles and M. Diaz, Biotechnol. Adv., 2013, 31, 1275-1291.

10 T. Kiryu, T. Kiso, H. Nakano and H. Murakami, Biosci., Biotechnol., Biochem., 2015, 79, 1712-1718.

11 S. Alonso, M. Rendueles and M. Diaz, Appl. Microbiol. Biotechnol., 2013, 97, 3843-3854.

12 S. Alonso, M. Rendueles and M. Diaz, Appl. Microbiol. Biotechnol., 2012, 96, 1465-1477.

13 F. H. Stodola and L. B. Lockwood, J. Biol. Chem., 1947, 171, 213-221.

14 S. H. Desai, C. A. Rabinovitch-Deere, Z. Fan and S. Atsumi, Microb. Cell Fact., 2015, 14, 52-61.

15 X. Li, K. Chomvong, V. Y. Yu, J. M. Liang, Y. Lin and J. H. Cate, Biotechnol. Biofuels, 2015, 8, 120.

$16 \mathrm{X}$. Zhou, X. Wang, R. Cao, Y. Tao, Y. Xu and S. Yu, BioResources, 2015, 10, 4277-4286.

17 M. F. Giraud and J. H. Naismith, Curr. Opin. Struct. Biol., 2000, 10, 687-696.

18 T. suzuki and H. Onishi, Agric. Biol. Chem., 1968, 32, 888893.

19 T. Nihira, Y. Saito, M. Nishimoto, M. Kitaoka, K. Igarashi, K. Ohtsubo and H. Nakai, FEBS Lett., 2013, 587, 3556-3561.

20 H. Gunnar, J. Gunnar and G. Pettersson, J. Biotechnol., 2000, 78, 93-113.

21 R. Nouaille, M. Matulova, V. Patoprsty, A. M. Delort and E. Forano, Appl. Microbiol. Biotechnol., 2009, 83, 425-433.

22 K. Goderska, A. Szwengiel and Z. Czarnecki, Appl. Biochem. Biotechnol., 2014, 173, 2189-2197.

23 R. C. Bean, G. G. Porter and B. M. Steinberg, J. Biol. Chem., 1961, 236(6), 1235-1240. 